\title{
Characteristic analysis of large-scale loess landslides: a case study in Baoji City of Loess Plateau of Northwest China
}

\author{
H. B. Wang ${ }^{1}$, B. Zhou ${ }^{1,2}$, S. R. Wu ${ }^{3}$, J. S. Shi ${ }^{3}$, and B. $\mathbf{L i}^{3}$ \\ ${ }^{1}$ School of Civil Engineering and Mechanics, Huazhong University of Science \& Technology, Wuhan 430074, China \\ ${ }^{2}$ Hubei Key Laboratory of Control Structure, Huazhong University of Science \& Technology, Wuhan 430074, China \\ ${ }^{3}$ Geomechanics Institute of China Geological Sciences, Beijing 100081, China
}

Received: 22 August 2010 - Revised: 25 April 2011 - Accepted: 28 April 2011 - Published: 5 July 2011

\begin{abstract}
Landslides are one of the most common geologic hazards in the Loess Plateau of northwest China, especially with some of the highest landslide densities found in Shaanxi and adjacent provinces. Prior to assessing the landslide hazard, a detailed landslide inventory map is fundamental. This study documents the landslides on the northwest Loess Plateau with high accuracy using high-resolution Quickbird imagery for landslide inventory mapping in the Changshou valley of Baoji city. By far the majority of landslides are in loess, representing small-scale planar sliding. Most of the large-scale landslides involve loess and bedrock, and the failure planes occurred either along the contacts between fluvial deposits and Neogene argillites, or partially within the bedrock. In the sliding zones of a large scale landslide, linear striations and fractures of the soils were clearly developed, clay minerals were oriented in the same direction and microorganism growths were present. From the analysis of microstructure of sliding soils, it is concluded that the Zhuyuan landslide can be reactivated if either new or recurring water seepage is caused in the sliding surface. It can be concluded that most landslides are attributed to the undercutting of the slope associated with gullying, and numerous ancillary factors including bedrock-loess interface, slope steepness, vegetation cover and land utilization.
\end{abstract}

\section{Introduction}

In China, loess mantles about $631000 \mathrm{~km}^{2}$, equivalent to about $6.6 \%$ of the total area (Liu, 1985), of which almost half is found on the Loess Plateau of Shaanxi Province. In

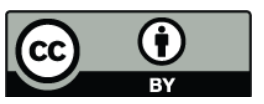

Correspondence to: H. B. Wang

(huabin@mail.hust.edu.cn) engineering circles, loess is known as a "problem soil", because of its catastrophic failure on reaching certain critical moisture content. Thus, landslides are one of the most common geologic hazards in the Loess Plateau, especially with some of the highest landslide densities found in Shaanxi and adjacent provinces. Historical records leave no doubt that the environment in this region is a harsh one, with unpredictable and violent monsoonal rainfall and frequent earthquake shaking. These principal triggers, together with a thick mantle of unconsolidated loess over mountainous bedrock terrain, render this undeveloped area subject to landsliding, causing property damage and fatalities. In addition, due to unreasonable land utilization and outmoded operation patterns, many steep slopes have been extensively cultivated, accelerating slope failure. To reduce the number of casualties and damage to property caused by landslides, factors that affect landslide occurrence should be well understood and the spatial location of landslides mapped.

In creating landslide inventory maps at different scales, there are at least a dozen earth-observation satellites currently collecting data on landslides, such as aerial photographs, SPOT and Landsat TM (e.g., Zhou et al., 2002; He et al., 2003). However, these satellite images have not been fully exploited in the study of landslides, due to the limited spectral and spatial resolution of conventional imagery, as summarized by Metternicht et al. (2005). For landslide hazard assessment, a scale of 1:25000 should be considered as the smallest scale to effectively analyse the slope stability phenomena using aerial photographs, however, limitations on recognizing the types and causes of landslides have been shown at scales smaller than 1:25000 in previous studies (Singhroy, 2002). Nowadays, with the availability of highresolution satellite imagery from Ikonos, Quickbird, SPOT-5, etc., new perspectives are open to the generation of landslide inventory maps on a larger scale of up to 1:5000 to 1:10000

Published by Copernicus Publications on behalf of the European Geosciences Union. 
(e.g., De la Ville et al., 2002; Yamaguchi et al., 2003; Nichol et al., 2006).

The Quickbird satellite, operative since October 2001, is a commercially available "next generation" satellite capable of collecting very high-resolution optical-image data. It acquires images at the highest geometric resolution and provides data with high quality, at up to $0.61 \mathrm{~m}$ in panchromatic mode and $2.44 \mathrm{~m}$ for the multispectral mode, depending on the off-nadir viewing angle. Through a combination of different images, Quickbird imagery has been orthorectified and employed in the detailed identification and detection of landslides, and monitoring of landslide activity (Chadwick et al., 2005; Delacourt et al., 2004). To meet the demands for landslide hazard assessment on a large scale ( $>1: 10000)$, an ideal map of slope instability hazard should provide information on the spatial-temporary probability, type, magnitude, velocity and runout distance (Dai et al., 2002). Thus, a detailed landslide inventory map is fundamental in assessing landslide hazard.

With the Quickbird imagery, a case study was conducted for landslide inventory mapping in a watershed of Baoji city, northwest Loess Plateau. This area is densely vegetated, so landslide indicators have been hard to identify, making landslide mapping problematic. Therefore, the objectives of this study were to document the landslides with high accuracy using high-resolution Quickbird imagery and to detect terrain changes by comparison to Digital Elevation Models (DEM) derived from a previously existing topographical map with 5 -m contour interval. The mechanisms of different landslides were also analysed based on the combinations of image interpretations and field investigations, and the microstructural analysis of sliding soils was conducted to explore the activity of a landslide.

\section{Description of study area}

Baoji city is located in western Shaanxi Province. From the view of a geomorphic landscape, rocky mountain, loess ridges and river flats appearing in this region, represent typical features of a faulted basin (Fig. 1). The Weihe basin, being a trans-tensional basin, is half-crescent shaped, about $350 \mathrm{~km}$ in length from Baoji eastward the Yellow River, and about $30-80 \mathrm{~km}$ in width from the Qinling Mountains and the Huashan Mountains northward to the Ordos Plateau. An intensive, uneven vertical movement of a fault zone occurred in the period from the Tertiary to the beginning of the Early Pleistocene, in which the Qinling Mountains and the Ordos Plateau uplifted and the Weihe graben basin was infilled by a 6000-m-thick accumulation of Neogene strata (Zhang et al., 1995). With a further uplift starting at the end of the Pliocene, lacustrine deposits changed from clays to fluvial gravel and sand sequences, and alternating layers of argillites, arenites and conglomerates were laid down. Due to the erosion of the Pliocene lacustrine basin by stream

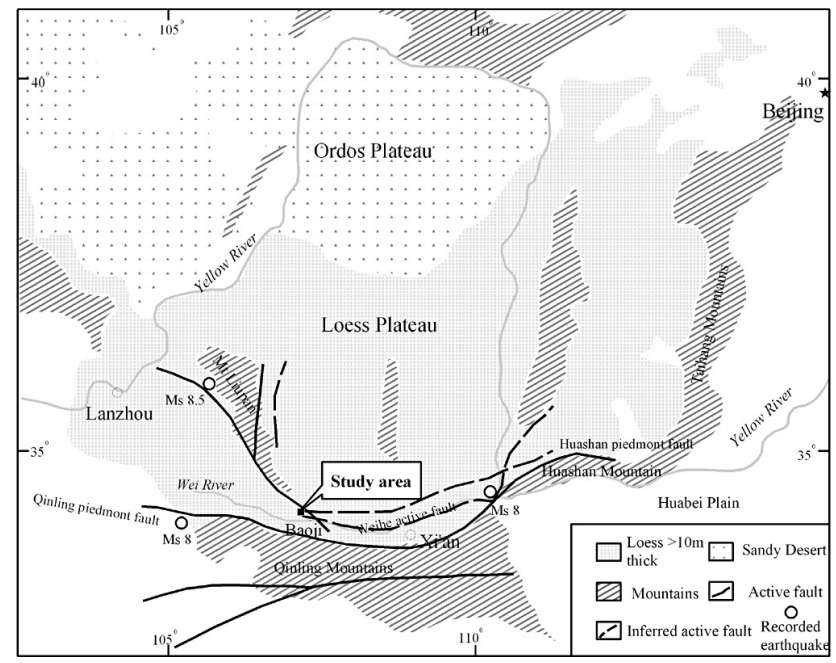

Fig. 1. Maps showing geological and geomorphologic information about Baoji city.

systems and reactivation of folds and faults, a very unstable base was formed for the extensive Quaternary loess deposits, which acts as the underlying cause of loess instability.

Historical records show that three earthquakes with $M_{\mathrm{s}} \geq 8$ occurred on Loess Plateau, as seen in Fig. 1, which triggered numerous landslides in the loess areas (Zhang et al., 1995; Derbyshire et al., 1999; Zhang and Wang, 2007). However, only three earthquakes with around $M_{\mathrm{s}}=3.5$ have been recorded in Baoji city and its adjacent area.

In the study area in the vicinity of Baoji city, the elevation ranges from 700 to $900 \mathrm{~m}$ a.s.l., while the average elevation on the Weihe River plain is $550 \mathrm{~m}$. The relative relief exceeds $100-350 \mathrm{~m}$ over the study area, i.e., the Changshou valley. Three main geomorphological units may be distinguished: dissected loess plateau (yuan), loess hills (mao) and loess ridges (liang) (Fig. 2). The lithology, of the strata in these units, is mainly the Neogene argillites and fluvial deposits consisting of clayey silts and gravels and Quaternary loess. In these units, the Neogene argillites are of particular importance to the study of landslides, as discussed in the next section.

The climate of the study area is noted for Asiatic monsoons, marked seasonal shifts in dominant winds being characteristic. The mean annual temperature varies from 7.6 to $12.9^{\circ} \mathrm{C}$, and the maximum is up to $41.6^{\circ} \mathrm{C}$. The mean annual precipitation reaches $710.24 \mathrm{~mm}$, and the maximum is $1163.3 \mathrm{~mm}$. Almost $50 \%$ of the precipitation falls in the period from July to September. The mean annual potential evapotranspiration exceeds $1161.1 \mathrm{~mm}$, and the maximum daily evapotranspiration is up to $248.8 \mathrm{~mm}$. 


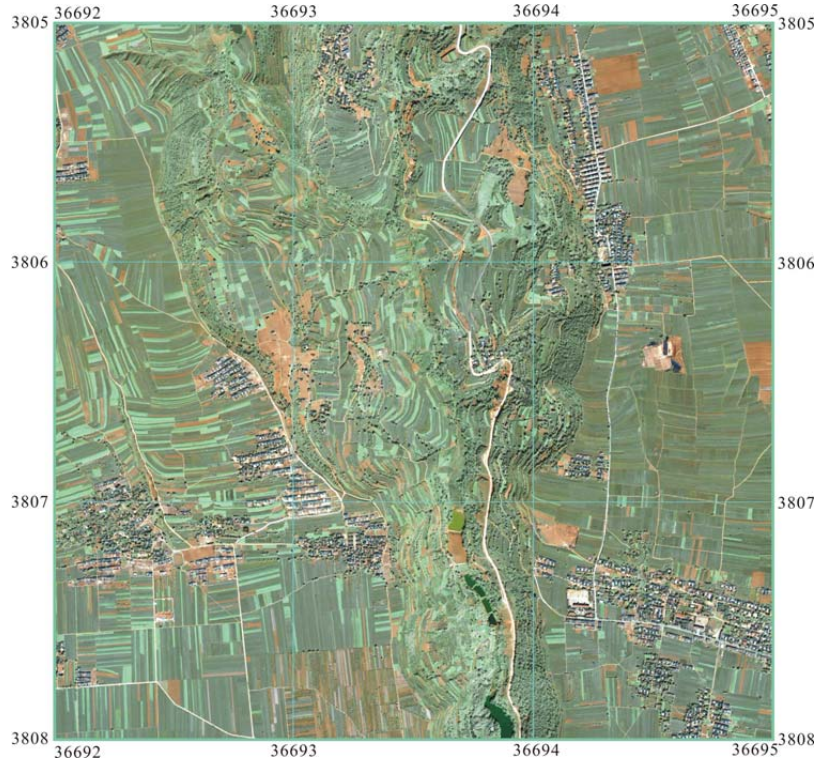

Fig. 2. Image showing geomorphological conditions of the Changshougou Valley.

\section{Data preparation}

\subsection{Satellite image processing}

Quickbird panchromatic and multi-spectral images were acquired on 16 May 2004, providing an 11-bit collected information depth, with a resolution of $1 \mathrm{~m}$. The imagery covers $548 \mathrm{~km}^{2}$ in Baoji city including the study area. In order to map landslides and collect information from Geographical Information Systems (GIS) databases, it is necessary not only to georeference them (assign real world coordinates), but also to remove all the distortions. To orthorectify the imagery, these distortions are removed using the accurate Digital Elevation Model (DEM), together with Ground Control Points (GCP), to calculate the exact location of every point in the photographs.

The Rational Polynomial Coefficients (RPC) sensor model was used to orthorectify data from the Quickbird sensors within ENVI 4.0. The PRC orthorectification process combines several sets of input data to place each pixel in the correct ground location, which was distinguished in ASTER DEM in 2003 with a resolution of $5 \mathrm{~m}$. First, the Quickbird panchromatic and multi-spectral images were ingested into ENVI, and then the ASTER DEM covering the study area occupied by the Quickbird images was provided. In addition, ground-control points that matched known features in the vector line work were identified in the images.

\subsection{Field investigation}

For the field investigation of landslides, the use of checklists for standardized data collection is important, but also time-consuming. Recent advances in mobile technologies, in particular, in hand-held computers and Personal Digital Assistants (PDA) have the potential to improve the field-data collection for mapping of landslides. To speed up this process considerably, numerous software packages for the developed mobile GIS have been used for digital geological field-data collections (e.g., Williams, 1997; Brodaric, 2000). Therefore, in this study, a novel data collection system, newly developed by the China Geological Survey, was employed for digital landslide mapping in the field, including landslide type, material involved, states of activity, causes and damage, etc. This mobile GIS operates in a Windows CE environment and PDA, and the system customizes the MapGIS (Chinese version). The system, integrated with GPS, is a quick and efficient way of creating digital landslide-inventory maps in the scope of MapGIS.

\section{Results and discussions}

\subsection{Types of landslides in loess}

There are a variety of landslides present in the Changshou valley. In order to properly describe landslide types in the loess area, a landslide classification is presented herein, following Varnes (1978) and Meng et al. (1999). Literature reviews and field investigations, thus, led to a practical classification based on the materials involved and the location of the failure plane in relation to the lithology. In addition, the examination of the Weihe River terraces and their overlying loess units has shown that landslides fall into three broad temporal categories, i.e., palaeo-landslides, old landslides and recent landslides. Palaeo-landslides occurred before or during the Pleistocene. The slide masses consist of materials of the Tertiary to Middle Pleistocene age, in which the late Pleistocene loess (Malan) sometimes occurs as a drape. Landslides of Late Holocene age involve materials of Late Pleistocene loess, which were developed entirely within loess. These kind of landslides were common in the study area. As a result of human activities, recent landslides were triggered or reactivated from other kinds of landslides. The principal mass movement types, recognized in the study area, are summarized in Table 1.

As can be seen in Fig. 3, there are three basic types of landslides that occur in a variety of materials based on the situation of the failure plane.

\subsection{Analysis of landslide mechanisms}

\subsubsection{Mixed landslide}

Combined loess and bedrock landslides were significantly shown in the study area. The failure planes for these landslides occurred either along the contacts between fluvial deposits and Neogene argillites, or partially within the bedrock. This kind of landslide includes a substantial percentage of 


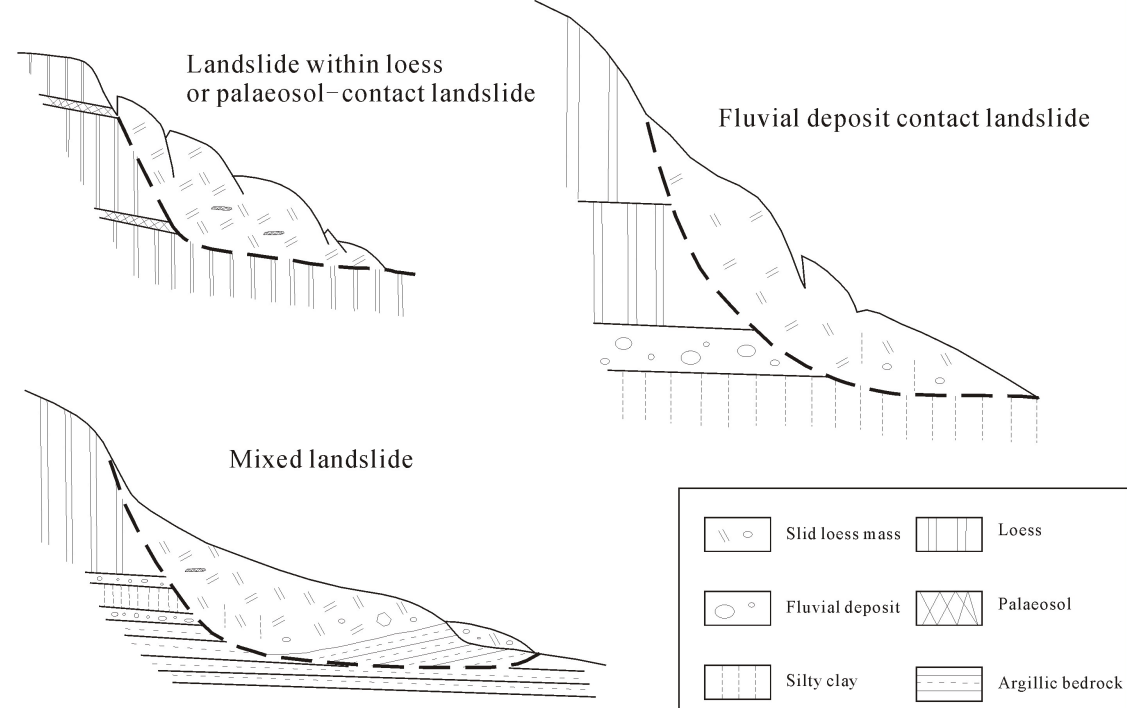

Fig. 3. Representative types of slope failures in the study area.

Table 1. Classification of landslide types in the study area.

\begin{tabular}{l}
\hline Type of material \\
\hline Mixed \\
Loess only \\
\hline Geometry and movement \\
\hline Flows and complex mass movements \\
Large rotational mass movements \\
Planar slides \\
Debris flows and mudflows \\
\hline Types based on situation of the failure plane \\
\hline Bedrock-contact landslides \\
Palaeosol-contact landslides \\
Mixed landslides \\
Landslides entirely within loess \\
\hline Age \\
\hline Palaeo-slides \\
Old slides \\
Recent slides \\
\hline
\end{tabular}

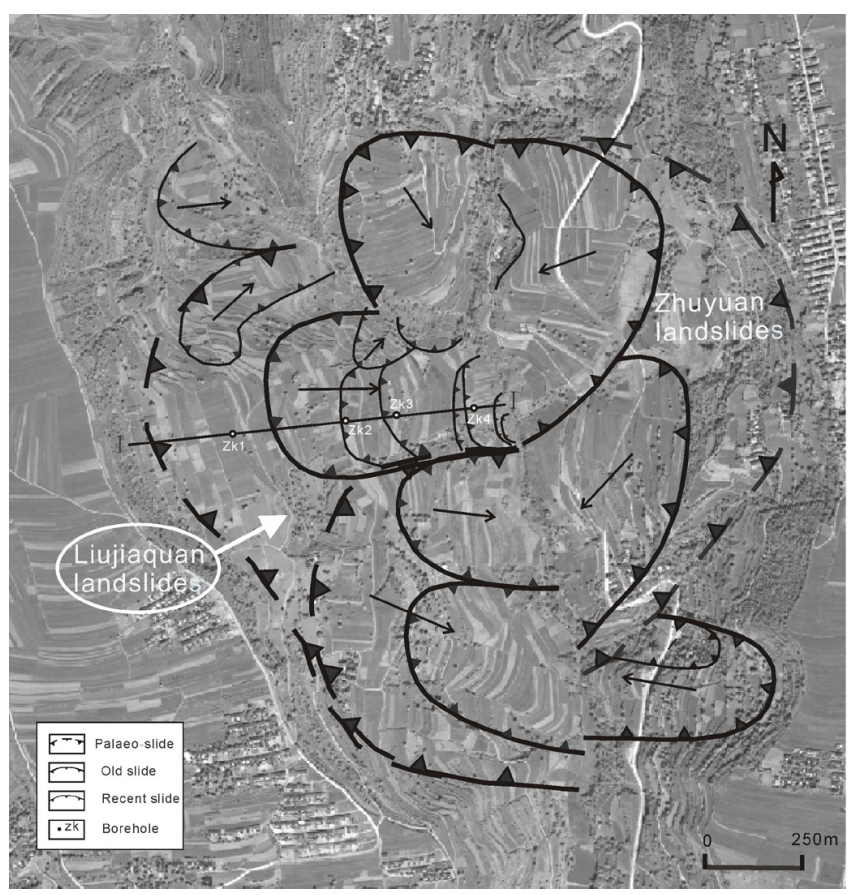

Fig. 4. View of the Zhuyuan and Lijiaquan landslides in a Quickbird image.

bedrock as large mass movements (failure surfaces $>100 \mathrm{~m}$ in depth) as noted by Meng et al. (1999). The mechanism of this type of landslide is shown for the Zhuyuan landslides in Fig. 4.

This landslide is located at Zhuyuan village, about $10 \mathrm{~km}$ north of Baoji. The landslide mass is $1000 \mathrm{~m}$ wide and $850 \mathrm{~m}$ long, with an estimated volume of $5.1 \times 10^{7} \mathrm{~m}^{3}$. A steeper slope is generally over $40^{\circ}$ around the crest, and a landslide terrace is forested. Remote-sensing interpretations and field

investigations of such a slide indicate a maximum vertical displacement of $150 \mathrm{~m}$ along the slip surface. The shape and slope angle of the landslide scars suggests a single, major semi-circular failure plane as indicated in Fig. 3c. At the Changshou valley floor, the slip surface dips about $10^{\circ}$ into the slope. Silty clays and argillites with gravels and grain sands were conglomerated in its shear zone (Fig. 5). 


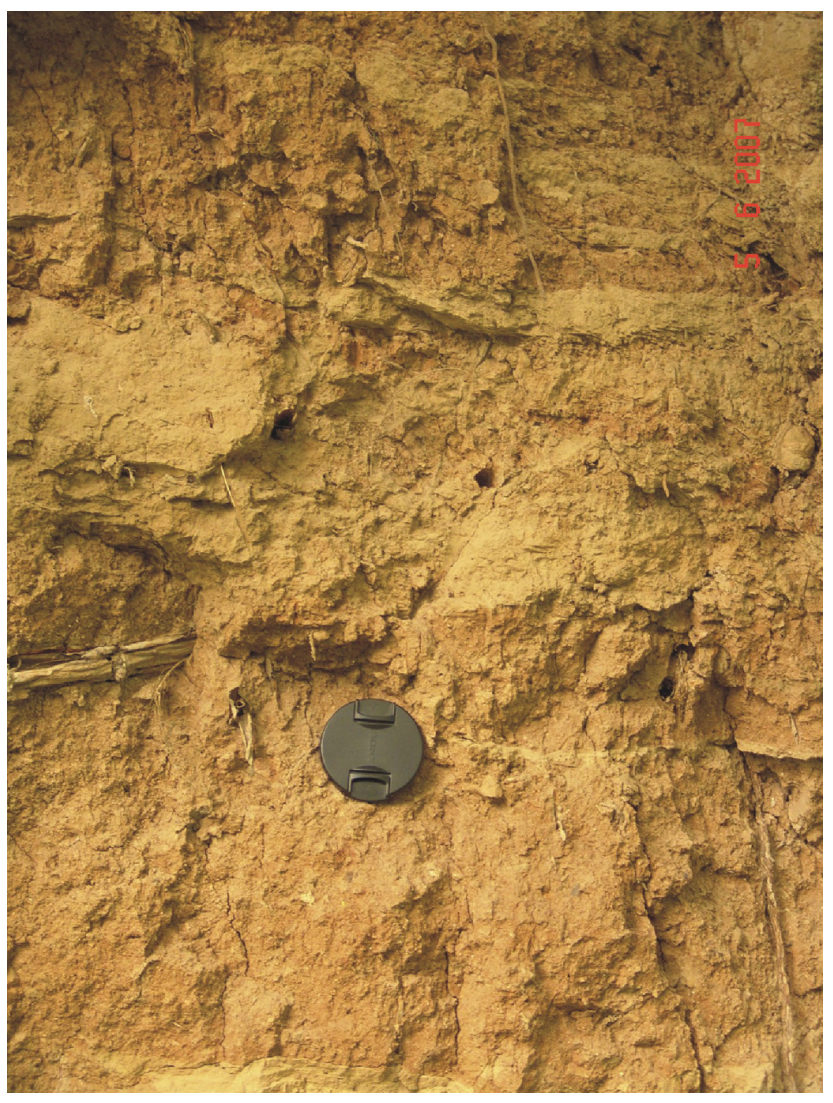

Fig. 5. Shear zone of the Zhuyuan landslide.

In the study area, the loess is about $150 \mathrm{~m}$ thick, and overlies bedrock of Neogene argillite dipping an average of $5^{\circ}$ southwest. During most of the year, the slope stability of loess is stable because the dry climate maintains undersaturated conditions. However, violent and prolonged rainfall events from July to September can saturate parts of the loess mantle, resulting in instantaneous disaggregation of the loess under its own weight. In addition, joint systems, initiated by the frequent unloading from erosion, influence the hydrology of the loess. The enlargement of sub-vertical and sub-horizontal joints can lead to the formation of extensive subsurface drainage channel networks capable of saturating the loess at greater depths; this provides conduits for the rapid transmission of water through the loess (Fig. 6). Collapse of the land surface can, thus, occur due to the resultant greater hydraulic conductivity after saturation of the loess. Further, the unconsolidated fluvial unit, consisting of silts and gravels, can store as much as the water transformed, while the argillites serve as lower-permeability bedrock.

For the Neogene argillite in the loess plateau, its clay minerals are dominated by illite, chlorite, smectite and kaolinite, similar to the overlying Quaternary loess (Peng and Guo, 2007). This kind of argillite is, thus, subjected to long-term softening due to the saturation in the contact zone. After a point is reached, at which they are no longer able to support the overlying loess, a progressive failure occurs.

The sudden occurrence and long runout in the behaviour of landslides in this area remain unexplained in the light of the existing theory of these phenomena. New insights into the landslide mechanism can provide reasonable explanations, i.e., the liquefaction of clays or clayey silts (Ter-Stepanian, 2000; Gratchev et al., 2006). The argillite and clayey silts become disturbed during the progressive motion, and in turn are liquefied. It was suggested, therefore, that excess pore pressures can be generated at the contact of the fluvial deposits and argillites, thus, leading to rapid long-out landsliding due to complete or partial liquefaction.

\subsubsection{A large-scale landslide}

At Liujiaquan village, loess thicknesses are around $170 \mathrm{~m}$ and comprise Wucheng, Lishi and Malan loess (70 m thick), mainly resting on Neogene argillites. Slopes on the Liujian River are affected by landsliding over a total length of about $2 \mathrm{~km}$, as shown in Fig. 4. The area affected by landslides is around $0.84 \mathrm{~km}^{2}$. The relative relief is locally as high as $200 \mathrm{~m}$, and slopes average $25^{\circ}$, as shown in Fig. 7.

There are 14 sub-landslides on the slope. Two palaeolandslides of Pleistocene age have severely degraded headwalls about $200 \mathrm{~m}$ above the present Liujian River. The main scarps are covered by dense forest, and the displaced mass has been utilised for irrigated and non-irrigated land, as well as for residences. The slide masses are composed of materials of Tertiary to Middle Pleistocene age, the youngest, Late Pleistocene loess (Malan), sometimes occurring as a drape. As exposed in borehole Zk1 (Fig. 7), linear striations and fractures of soils in sliding zones were clearly developed (Plate 1). Three old landslides can be found in the irrigated land. The northern old slide was reactivated and, thus, eight recent landslides were present, as shown in Fig. 4. As observed in the field investigation, the land utilisation for irrigation and undercutting of toes by river erosion made major contribution to the reactivation of these masses. For the other two old slides, the average gradient of landslides was about $20^{\circ}$ after movement had ceased. Lots of small cliffs had formed within it, sometimes due to cultivation, so that the slide masses were still extremely loose. Heavy seasonal rainfall resulting in saturation at the base caused by continuing seepage can lead to renewed triggering of the whole landslide body.

There is strong bedrock control on the loess geomorphology in this area. Erosion of the fluvial and lacustrine deposit in the Baoji basin during the Late Pliocene resulted in the development of palaeo-relief, albeit enhanced by subsequent loess deposition. Intensive weathering under warm, humid conditions resulted in the formation of a weather crust enriched in swelling clay minerals, including smectites and montmorillonites. In particular, the weathered nature of the 


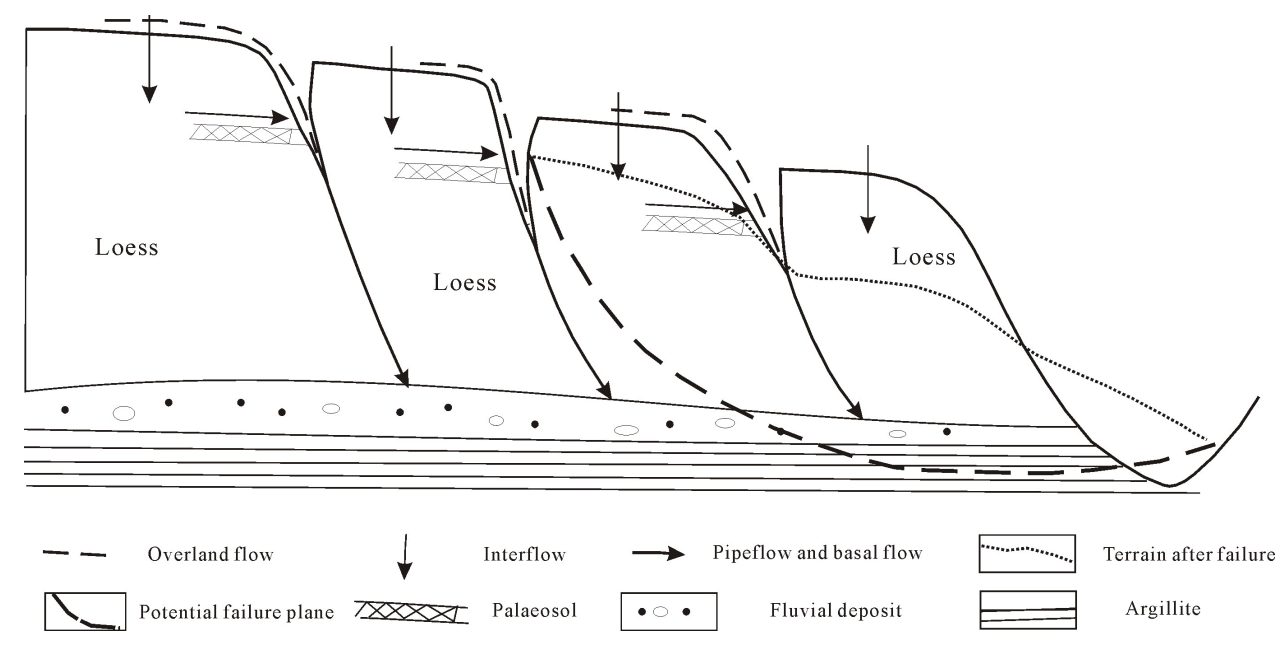

Fig. 6. Schematic model of water routing in loess at the study area.

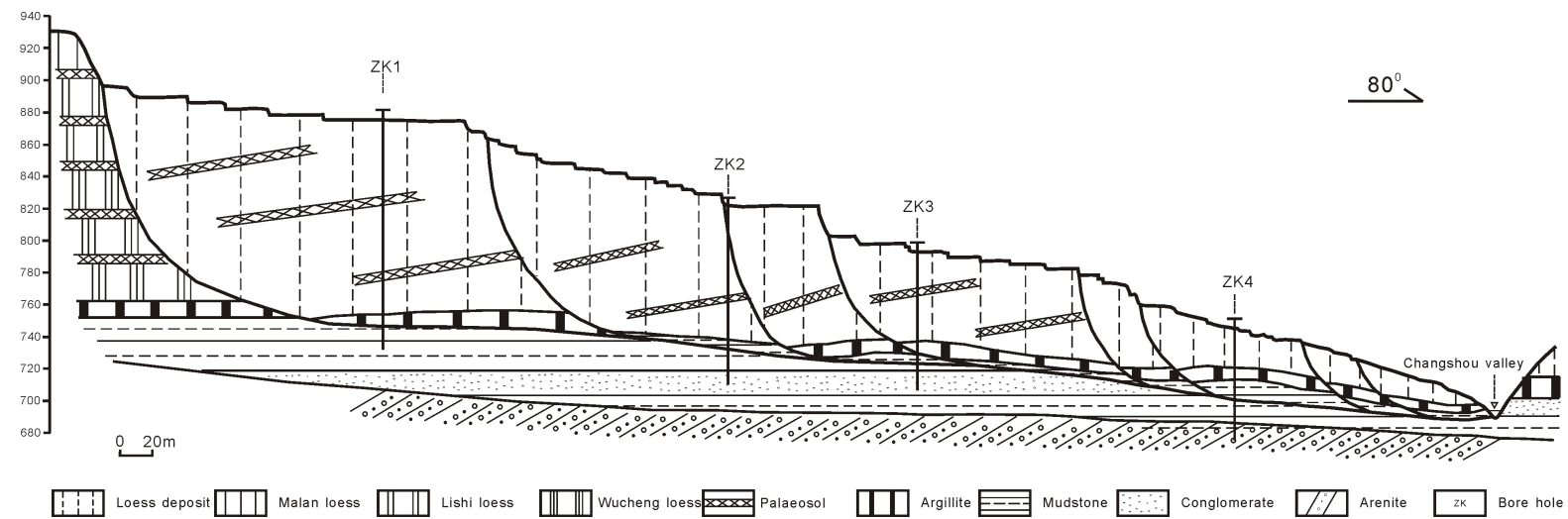

Fig. 7. Geological cross-section through the Liujiaquan landslides.

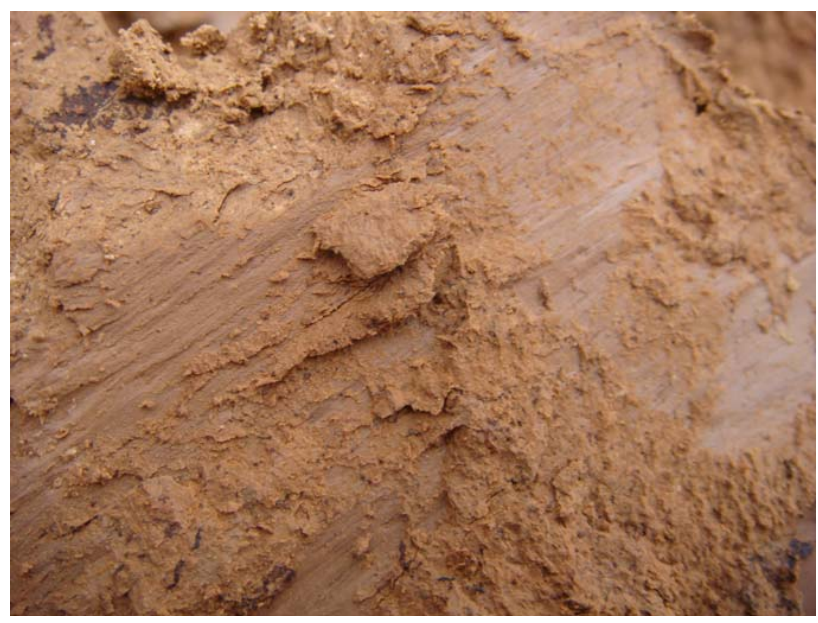

Plate 1. Linear striations of soils along the main sliding surface of the Liujiaquan landslide. bedrock surface created an environment of enhanced instability along the loess-bedrock contact zone.

On the basis of site investigations, it is concluded that the initiation of a number of these landslides is attributed to the undercutting of the slope associated with gullying. Initiation of recent mass movements is due to extensive piping systems and the build-up of a seasonal groundwater table in the conglomerates. The sustained saturation of the upper layers of the Neogene bedrock has resulted in an increase in moisture content. This increase can lead to softening of the argillites, thus, the shear strength of the argillites decreases significantly.

\subsubsection{Microstructural analysis of soils along the sliding surface}

The Scanning Electron Microscope (SEM) has been frequently employed to analyse the microstructure of soils in an attempt to assess their environmental and mechanical behaviour (Mitchell, 1993). As an effective method to analyse 


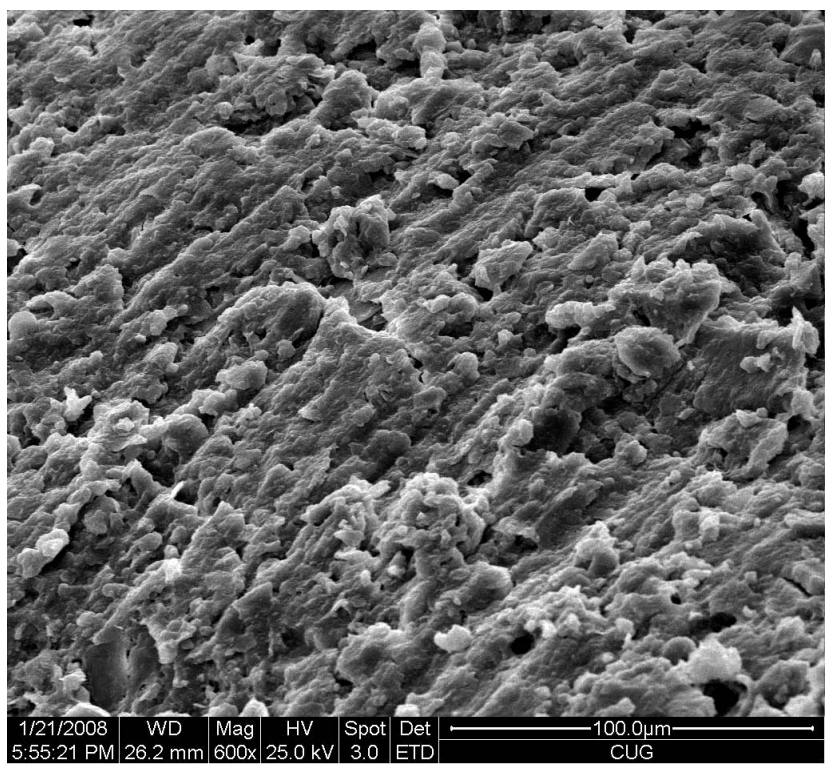

Plate 2. Linear striations and fractures of soils along the sliding surface of the Zhuyuan landslide.

landslide mechanisms, especially to know the movement of sliding soils at microscale, SEM has been used to obtain insight into how often sliding has occurred and how the sliding surface evolved from observation of soil samples from the sliding surface (Wang et al., 2005). To understand the main activity of the Zhuyuan landslide on a microscale, field samples were collected within the upper slip zones; the microstructures of these soils along the sliding surface were analysed by SEM. The collected samples were kept in their original state and sealed in dry conditions to enable analysis of microorganisms and soil-surface structures. After the samples were prepared, soil microstructures were observed under SEM.

In the sliding zones of the Zhuyuan landslide, linear striations and fractures of the soils were clearly developed (Plate 2), clay minerals were oriented in the same direction (Plate 3), microorganism growths were present (Plate 4). With regard to linear striations, the landslide activity can be interpreted by stick slip at the first stage of activity. Meanwhile, the clay mineral was deformed by extrusion stress after slope failure was oriented in the same direction, and the existing linear striation can make the sliding soil decrease in its strength. The microorganism was presented by filamentous fungus. Their specific surface area can be large, and water absorbing capacity is strong to make the soil rich. The presence of microorganism can make the slope reactivate if rainfall or water level changes occur in the study area. As found in the previous description of water routing in loess in the study, the enlargement of sub-vertical and sub-horizontal joints, including sliding surfaces, can lead to the formation of extensive subsurface drainage channel networks capable of saturating the loess at greater depths; this provides conduits

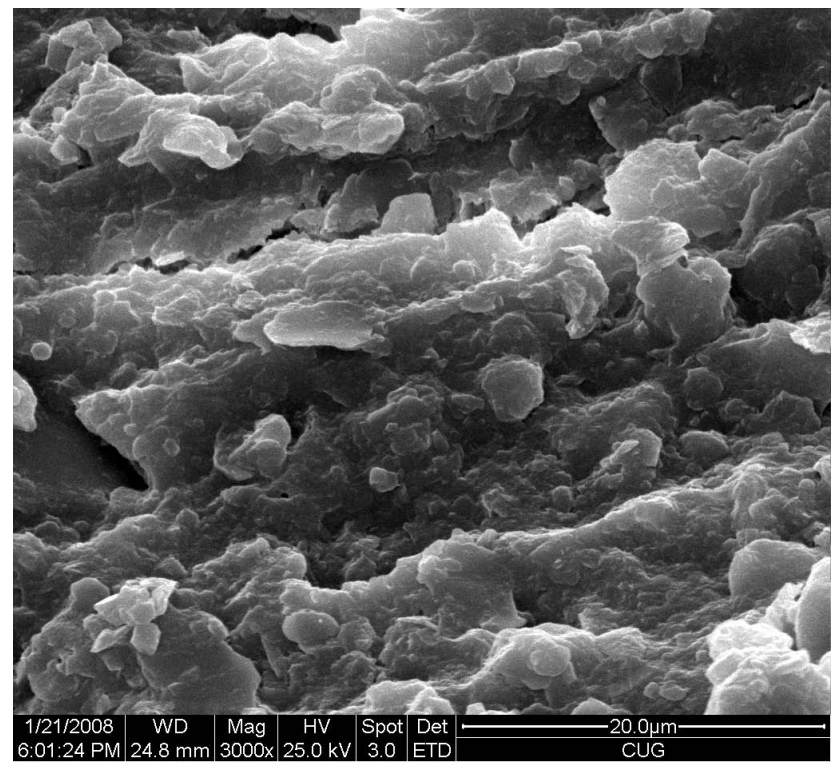

Plate 3. Directional array of clay minerals in soils along the sliding surface of the Zhuyuan landslide.

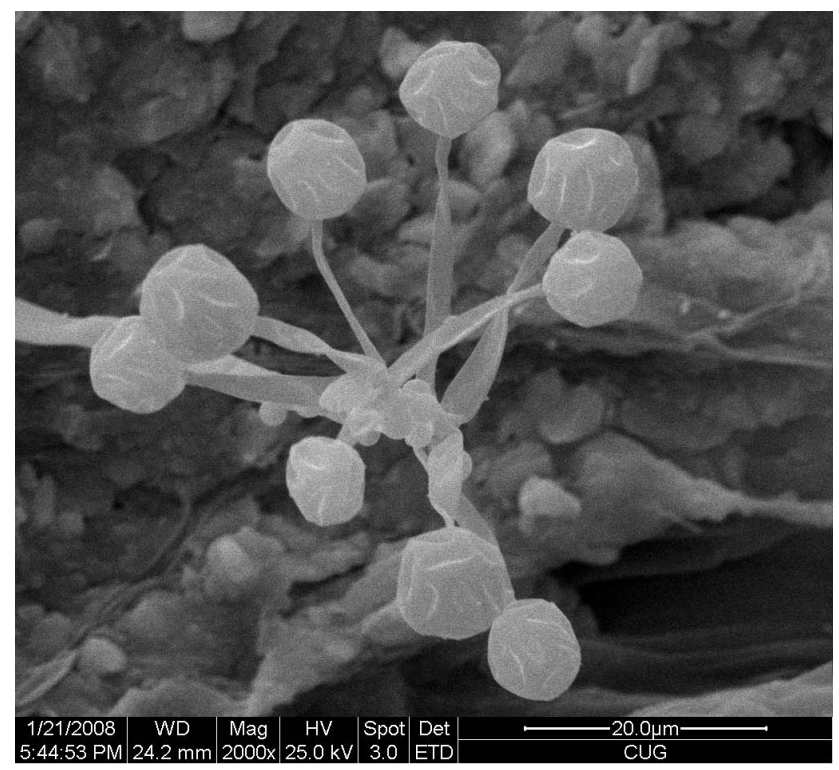

Plate 4. Filamentous fungus distributed in soils along the sliding surface of the Zhuyuan landslide.

for the rapid transmission of water through the loess. It is concluded that the Zhuyuan landslide can be reactivated if either new or recurring water seepage occurs in the sliding surface.

\subsubsection{Factors affecting landslide occurrence}

As described in the previous section, these landslides are attributed to the undercutting of the slopes associated with 
gullying. Major variables affecting the initiation of slope failure and subsequent modes of movement appear to be dependent upon morphology, the nature and degree of weathering of the underlying bedrock and the moisture status of the loess deposits. Numerous ancillary factors include bedrock-loess interface, slope steepness, vegetation cover and land utilization. As already noted, the upper surface of the Neogene bedrock is often weathered and contains variable amounts of smectites. In this zone, repeated wetting results in a progressive decrease in strength that may ultimately lead to slope failure. Undercutting of the slopes along the gullies is frequent, increasing the risk of slope failure. As a result of high relative relief, the steep slopes and the relatively uniform geological and geomorphological conditions, the landslides tend to be very large and occur in groups.

Most ancient landslides are not traceable in the historical records and some recent landslides are still moving. Undercutting of the toes of landslides and land utilization frequently cause reactivation. For this kind of triggering, planar slides are commonly present, about 1 to $5 \mathrm{~m}$ thick. These slides move as essentially rigid bodies over shallow slip surfaces. Failure appears by the sliding of a slab of loess on a slip surface parallel to the ground surface. The occurrence of planar slides in the study area depends on shear-strength conditions on the failure surface and the cohesion of the material involved. These slides usually occur in the Malan loess and in reworked loessial slope deposits.

\section{Conclusions}

Landslides in the mountainous loess region of Baoji City are triggered by frequently severe summer monsoonal rains. Prior to assessing landslide hazard, a detailed landslide inventory map is fundamental. This study documents the landslides with high accuracy using high-resolution Quickbird imagery for landslide hazards in the watershed of Baoji city, northwest Loess Plateau and detects terrain changes by a comparison to Digital Elevation Models (DEM) derived from a topographical map with 5-m contour lines.

Landslides in the Changshou valley are classified based on the materials involved and the location of the failure plane in relation to the lithology. Landslides are also classified according to age as palaeo-slides, old slides and recent slides. By far the majority of landslides are in loess, representing small-scale planar sliding. Most of the large-scale landslides involve loess and bedrock, and the failure plane occurred either along the contact between fluvial deposits and Neogene argillites, or partially within the bedrock.

In the sliding zones of a large-scale landslide, linear striations and fractures of the soils were clearly developed, clay minerals were oriented in the same direction, and microorganism growths were present. From the analysis of microstructure of sliding soils, it is concluded that the Zhuyuan landslide can be reactivated if either new or recurring water seepage is caused in the sliding surface.

It can also be concluded that most of the landslides are attributed to the undercutting of the slope associated with gullying, and numerous ancillary factors including bedrockloess interface, slope steepness, vegetation cover and land utilisation.

Acknowledgements. This research was supported by funding from National Nature Science Foundation of China (NSFC) (Nos. 40772170) and Key Programme of Natural Science Foundation of Hubei (2009CDA007). In addition, partial support from the Doctoral Fund from Ministry of Education of China (20100142110059) is acknowledged with thanks. Spatial thanks go to the Fundamental Research Funds for the Central Universities (HUST2010MS057).

Edited by: T. Glade

Reviewed by: S. Bai

\section{References}

Brodaric, B.: Field data capture and manipulation using GSC fieldlog v3.0. Available online, USGS Open-file Report 97-269, available at: http://pubs.usgs.gov/of/1997/of97-269/brodaric. html (last access: 20 July 2010), 2000.

Chadwick, J., Dorsch, S., Glenn, N., Thackray, G., and Shilling, K.: Application of multi-temporal high-resolution imagery and GPS in a study of the motion of a canyon rim landslide, ISPRS, J. Photogramm., 59, 212-221, 2005.

Dai, F. C., Lee, C. F., and Ngai, Y.: Landslide risk assessment and management: An overview, Eng. Geol., 64, 65-87, 2002.

De la Ville, N., Diaz, A. C., and Ramirez, D.: Remote sensing and GIS technologies as tools to support sustainable management of areas devastated by landslides, Environ. Sustain. Dev., 4, 221229, 2002.

Delacourt, C., Alleman, P., Casson, B., and Vadon, H.: Velocity field of the "La Clapiere" landslide measured by the correlation of aerial and QuickBird satellite images, Geophys. Res. Lett., 31, L15619, doi:10.1029/2004GL020193, 2004.

Derbyshire, E., Wang, J. T., and Meng, X. M.: A treacherous terrain: background to natural hazards in northern China, with special reference to the history of landslides in Gansu Province, in: Landslides in the thick loess terrain of north-west China, edited by: Derbyshire, E., Meng, X. M., and Dijkstra, T. A., 11-18, 1999.

Gratchev, I. B., Sassa, K., Osipov, V. I., and Sokolov, V. N.: The liquefaction of clayey soils under cyclic loading, Eng. Geol., 84, 70-84, 2006.

He, Y. P., Xie, H., Cui, P., Wei, F. Q., Zhong, D. L., and Gardner, J. S.: GIS-based hazard mapping and zonation of debris flows in Xiaojiang Basin, southwestern China, Environ. Geol., 45, 285293, 2003.

Liu, T. S.: Loess and the environment, Science Press, Beijing, 215 pp., 1985.

Meng, X. M., Dijkstra, T. D., and Derbyshire, E.: Loess slope instability, in: Landslides in the thick loess terrain of north-west China, edited by: Derbyshire, E., Meng, X. M., and Dijkstra, T. A., 175-181, 1999. 
Metternicht, G., Hurni, L., and Gogu, R.: Remote sensing of landslides: An analysis of the potential contribution to geo-spatial systems for hazard assessment in mountainous environments, Remote Sens. Environ., 98, 284-303, 2005.

Mitchell, J. K.: Fundamentals of Soil Behaviour, Wiley, New York, 1993.

Nichol, J. E., Shaker, A., and Wong, M. S.: Application of highresolution stereo satellite images to detailed landslide hazard assessment, Geomorphology, 76, 68-75, 2006.

Peng, S. Z. and Guo, Z. T.: Clay mineral composition of the Tertiary red clay and the Quaternary loess-palaeosols as well as its environmental implication, Chinese J. Quaternary Sci., 27, 277-285, 2007.

Singhroy, V. H.: Landslide hazards: CEOS, The use of earth observing satellites for hazard support: Assessments and scenarios, Final report of the CEOS Disaster Management Support Group, NOAA, 98 pp., 2002.

Ter-Stepanian, G.: Quick clay landslides: their enigmatic features and mechanism, B. Eng. Geol. Environ., 59, 47-57, 2000.

Varnes, D. J.: Slope movement types and processes, in: Landslides: analysis and control, edited by: Schuster, R. L. and Krizek, R. J., National Academy of Sciences, Transportation Research Board, Special Report 176, 11-33, 1978.
Wang, H. B., Xu, W. Y., and Xu, R. C.: Slope stability evaluation using Back Propagation Neural Networks, Eng. Geol., 80, 302315, 2005.

Williams, V.: Using the GSMCAD program with GPS data collection in the field and as a quick and efficient way of creating Arc/Info geologic map coverages, US Geological Survey Openfile Report 97-269, available at: http://pubs.usgs.gov/of/1997/ of97-269/williams.html (last access: 9 June 2009), 1997.

Yamaguchi, Y., Tanaka, S., Odajima, T., Kamai, T., and Tsuchida, S.: Detection of a landslide movement of SPOT HRV data of two different dates, Int. J. Remote Sens., 24, 3523-3534, 2003.

Zhang, A. L., Yang, Z. T., Zhong, J., and Mi, F. S.: Characteristics of late Quaternary activity along the southern border fault zone of Weihe graben basin, Quatern. Int., 25, 25-31, 1995.

Zhang, D. X. and Wang, G. H.: Study of the 1920 Haiyuan earthquake-induced landslides in loess (China), Eng. Geol., 94, 76-88, 2007.

Zhou, C. H., Lee, C. F., Li, J., and Xu, Z. W.: On the spatial relationship between landslides and causative factors on Lantau Island, Hong Kong, Geomorphology, 43, 197-207, 2002. 